\title{
Internasionalisasi Pendidikan dan Strategi Pengembangan Mutu Perguruan Tinggi Agama Islam di Indonesia: Sketsa Edukatif Manajemen Mutu
}

\author{
Thoyib $^{*}$
}

\begin{abstract}
Abstrak
Internationalization is truly acceleration into all fields that able to pierce the limit of field and regional otorities of a state, or on Robertson's view (2003), internationalization is the third wave of globalization, that able to accompany a state becoming superior or on the contrary, will be falling out. The existence and success of higher education especially for Islamic Higher Education in Indonesia (PTAI) in the globalization era and liberalization of education in the future will be decided so much by the seatle of akademic and educational infrastructures preparation of the higher education and has more farther at international competition level without lossing Islamic morality character as its basic application. This assumtion also has to be supported by more better strategies for developing quality system of Islamic higher education; first, management of higher education at Islamic higher education (PTAI) should be able to concentrate for international academic quality development. Strengthening its management should be supported by; (1) implementation of acreditation for regional and international scales, (2) otonomy of

* Penulis adalah dosen pada Sekolah Tinggi Agama Islam Negeri (STAIN) Ponorogo Jawa Timur sekaligus alumni Prodi Tarbiyah (PAI) FIAI UII Yogyakarta.
\end{abstract}

NO. 2. VOL. I. 2008

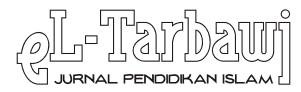


organizing higher education that more established with empowering local and national potentialities, (3) accuntability of Islamic higher education aplication supported by the whole stakeholders, and (4) competencies of infrastructures and human resources at Islamic higher education is always improved through resources improvement policy. Second, aplication of quality management should be supported by good academic atmosphere implemented on the whole stakeholder's commitment for achieving more better quality of Islamic higher education in the next future. Third, humanistic sense of diversity has to becoming primary supporting tool for Islamic higher education to face internationalization application more humanistic and large international academic networking for supporting Indonesia's human resources becoming qualified, productive, innovative and competitive in all competition scales.

Keywords: Internationalization of education, Islamic Higher Education, educational quality management

\section{A. Pendahuluan}

Seiring dengan derasnya arus kompetisi global di dunia pendidikan tinggi pada milenium ketiga ini membuat banyak perguruan tinggi terutama PTAI di Indonesia acapkali kesulitan untuk mengikuti perkembangannya, terutama Perguruan Tinggi Agama Islam Swasta (PTAIS) yang notabene secara kualitas dan instrumentasi pendidikannya masih jauh dari apa yang diharapkan. Dampaknya, banyak di antara mereka yang mengalami nasib yang mengenaskan, atau 'gulung tikar'.

Realitas itu selanjutnya membawa dampak yang luar biasa terhadap munculnya image kesenjangan kualitas antara PTN dan PTS yang pada akhirnya memunculkan pandangan dikotomis bahwa PTN merupakan perguruan tinggi yang memiliki mutu yang lebih baik daripada PTS. Kondisi ini membuat masyarakat lebih percaya dan cenderung memilih PTN umum (contoh ITB,UI, UGM dan lain sebagainya) dibanding dengan perguruan tinggi Islam (contoh UIN), apalagi bila dibandingkan dengan perguruan tinggi internasional, baik di dalam maupun diluar negeri seiring dengan arus liberalisasi pendidikan dunia, sektor row out put pendidikan tinggi PTAI di Indonesia sangat jauh tertinggal. Realitas itu menuntut kerja 
keras PTAI untuk mengembalikan the golden age of Islam di Indonesia, dalam bahasa Abdurrahman Mas'ud (2001: 13) sebagai kiblat Negara muslim terbesar di dunia. Minimal mampu berkancah di level Asia

Alasan ini berdasarkan pada fenomena dan kenyataan di lapangan bahwa PTAI selalu kalah bersaing dalam menghasilkan out put yang siap dipakai. Buktinya, hampir $43 \%$ lulusan PTAI tiap tahunnya tidak mampu terserap oleh dunia kerja, baik di sektor publik maupun nonpublik (Ahmad Rivan, 2005) Meminjam bahasa Mark Haynes Daniel (2002: 34), scary but true, menakutkan tetapi benar. Artinya kondisi demikian sangat memprihatinkan dan perlu perhatian yang serius dari PTAI di Indonesia. Belum lagi dewasa ini, PTAI di Indonesia (semisal UIN maupun STAIN) masih mempunyai dualisme paradigma, yaitu masih memisahkan perkembangan ilmu pengetahuan dan teknologi dengan pengetahuan agama. Adapun tuntutan masyarakat abad 21 sebagai masyarakat ilmu pengetahuan (knowledge society) menuntut setiap individu menguasai ilmu pengetahuan tanpa harus kehilangan nilai-nilai agama. Fenomena yang terjadi di Perguruan Tinggi Islam Negeri ini juga terjadi pula pada Perguruan Tinggi Agama Islam Swastanya.

Kondisi pendidikan tinggi yang sedemikian memprihatinkan itu semakin diperparah oleh fakta bahwa kualitas Sumber Daya Manusia (SDM) kita yang masih rendah. Oleh sebab itu, sebenarnya kita patut khawatir terhadap kemampuan bersaing SDM kita di era globalisasi pada milenium ketiga ini. Betapa tidak, data yang dipublikasikan oleh United Nations Development Progam (UNDP) (Suyanto dan Djihad Hisyam, 2000: 4) menegaskan bahwa pada tahun 1996, kualitas SDM kita berada pada posisi yang sangat memprihatinkan, yaitu berada pada peringkat 102 dari 174 negara di dunia. Bahkan pada tahun 2007, Indonesia makin terpuruk di posisi 112, di bawah Malaysia (61), Thailand (73), Filipina (84) dan Vietnam (108) (Ferry Salim, 2007). Laporan UNDP itu memuat angka indeks kualitas SDM (Human Development Index-HDI) yang mencakup 3 hal; tingkat pendidikan, kesehatan serta ekonomi rata-rata masyarakat.

Hasil laporan itu harus menjadi 'cambuk' bagi kita untuk terus secara simultan membenahi kondisi pendidikan tinggi Islam PTAI di negeri ini karena untuk menghadapi abad 21 ini yang salah satu cirinya ditandai dengan lahirnya suatu masyarakat mega-kompetisi, yaitu suatu masyarakat 
yang mampu berkompetisi dengan baik dan mempunyai kesadaran global (global consciousness). Oleh karena itu, pembenahan pendidikan tinggi Islam terutama PTAIS menjadi suatu tuntutan yang mutlak untuk dilakukan menuju perubahan kualitas serta eksistensi lembaga pendidikan yang lebih baik di masa yang akan datang. Hal ini selaras dengan apa yang pernah dikatakan oleh Kennedy (Suyanto dan Djihad Hisyam, 2000: 22), "Change is a way of life. Those who look to the past or present will miss the future." Artinya, dalam melakukan reformasi pendidikan kita harus berpegang pada tantangan masa depan yang penuh dengan persaingan global agar mampu berkompetisi secara baik.

Dalam konteks internasionalisasi pendidikan tinggi Islam sebagai konsekuensi upaya surviving PTAI di era global saat ini, pemakalah melalui tulisan ini ingin memberikan sedikit sumbangsih pemikiran dalam rangka pengembangan perguruan tinggi agama Islam (PTAI) di Indonesia agar lebih eksis dan survive di era kompetisi global tersebut. Tulisan ini secara garis besar memuat 4 gagasan besar yang cukup urgen, yaitu; (1) Sketsa historis peran strategis PTAI di Indonesia, (2) Paradigma internasionalisasi pendidikan dalam wacana internasionalisasi pendidikan tinggi Islam di Indonesia, (3) Strategi dan prospek pengembangan pendidikan tinggi Islam dalam aplikasi internasionalisasi pendidikan pada PTAI di Indonesia, serta (4) Manajemen mutu sebagai perangkat obligatif operasional mutu sistem internasionalisasi pendidikan tinggi pada PTAI di Indonesia.

\section{B. Pembahasan}

\section{Sketsa Historis Peran Strategis PTAI di Indonesia}

Secara historis, perguruan tinggi agama Islam dalam kontelasi pemberdayaan umat di Indonesia memiliki peran yang sangat urgen, baik secara struktural maupun kultural dari masa penjajahan, kemerdekaan hingga saat ini. Azyumardi Azra (2000: 51) mengemukakan bahwa setidaknya ada 2 peran strategis PTAI di Indonesia. Pertama, peran struktural organisasional. Peran ini berfungsi membentuk dan menciptakan kader-kader akademis intelektual muslim masa depan yang diharapkan mampu menjadi lokomotif pembaharuan pemikiran keislaman Indonesia 
ke arah modernisasi perangkat-perangkat infrastruktur pendidikan Islam di masyarakat. Fungsi ini selama ini banyak diperankan oleh lembaga pendidikan tinggi Islam baik swasta maupun negeri. Dengan adanya peran itu, masyarakat memiliki academic conciousness sehingga mampu memposisikan dirinya dalam pergulatan sosial politik keagamaan secara moderat.

Kedua, peran sosial kultural. Peran ini oleh PTAI dimediasikan melalui gerakan pengabdian dan social research dengan melibatkan berbagai lapisan masyarakat. Peran ini juga tidak kalah penting, karena dengan pendekatan itu PTAI mampu menjalin social network dengan masyarakat sebagai salah satu stakeholder serta mendorong tumbuhnya social confidence dan spirit of ethics otonomy masyarakat yang bertumpu pada Islamic morality values sehingga mampu menciptakan tatanan masyarakat yang beradab, sehingga wajar jikalau kemudian Indonesia menjadi center of Islamic episentrum negara muslim dunia, atau menurut Daniel S. Live (dalam Mastuhu, 2004: 25), Indonesia is the most moderate countries yang tidak hanya kokoh akan tradisi multikulturalismenya, tetapi juga memiliki komitmen yang tinggi akan tradisi keislamaannya. Wajar jikalau kemudian Barat lebih berkiblat ke Indonesia dalam konteks kajian keislaman.

Ketiga, secara spiritualitas, menurut penulis, PTAI juga memiliki peranan yang tidak kalah besar, yaitu dalam membentuk masyarakat agar memiliki kesadaran keagamaan (religious consiousness). Agama menjadi platform human life agar manusia tidak terasing dengan lingkungan dan tuhannya. Peran spiritualitas inimenjadipenting terutama dalammengarungi fase era globalisasi dan liberalisasi, yang oleh Gary Zukav (1991: 125) disebutnya sebagai era blind of materialism. Artinya segala sesuatu banyak dipatok berdasarkan ketentuan materi tanpa memperhitungkan kondisi psikologis manusia. Dampaknya banyak manusia yang mengalami stres dalam segala bidang kehidupan, termasuk dalam hal pendidikan pula. Misalnya saja, berdasarkan hasil penelitian Straith Time, pada tahun 2003, ada 5\% anak Singapura menderita stres berat sebagai implikasi dari globalisasi pendidikan.

Dalam konteks itu pula, upaya pembenahan kualitas di PTAI terutama PTAIS ini menjadi tanggungjawab yang besar dan berat bagi kita, namun akan menjadi suatu kebanggaan bagi kita apabila mampu memberikan 
konstribusi yang signifikan bagi peningkatan mutu pendidikan di negeri ini, karena dalam sejarah perkembangannya di Indonesia, menunjukan kepada kita betapa besarnya peranan PTAI di dalam meningkatkan kehidupan intelektual, kultural dan sosial bangsa Indonesia. Menurut Tilaar (2001: 83), upaya untuk meningkatkan mutu pendidikan nasional, tidak bisa mengabaikan eksistensi dan keikutsertaan PTAI sebagai sebuah lembaga pendidikan tinggi Islam. Fakta itu ditunjukkan dengan angka partisipasi PTAI dari tahun ke tahun yang semakin besar. Pada tahun 1993, jika angka partisipasi pendidikan tinggi nasional itu $8.5 \%$ dengan jumlah mahasiswa 1,6 juta, maka pada akhir tahun 1994 angka partisipasi itu meningkat menjadi $11.00 \%$ dengan jumlah mahasiswa sekitar 2.5 juta. Sebagian besar kenaikan jumlah mahasiswa itu ditampung oleh PTAIS. Hal ini menunjukkan betapa besar peran PTAI dalam membantu meningkatkan kualitas SDM di negeri ini.

Kenyataan tersebut menegaskan betapa besar peran PTAI di Indonesia, terlepas dari berbagai kelemahan yang ada hingga kini. Oleh karena itu, sudah menjadi suatu keharusan bagaimana PTAI di Indonesia tanpa termangu dengan historisitas peran strategis yang telah diberikan bagi pengembangan dan kemajuan negara ini untuk terus melakukan pembenahan secara simultan, dan kontinyu untuk menjadi lebih baik sehingga ke depan dapat lebih meneguhkan jati dirinya sebagai kawacandradimuka pemberdayaan umat Islam sekaligus mempertajam orientasi peran futuristiknya bagi generasi yang akan datang sehingga akan lebih akamodatif dan adaptif terhadap berbagai persoalan keummatan di era globalisasi dan internasionalisasi pendidikan. Tanpa didukung adanya internal conciousness for improvement untuk terus eksis, maka tidak mungkin PTAI di Indonesia dapat melanjutkan kiprah strategisnya di masa-masa yang akan datang.

\section{Paradigma Internasionalisasi Pendidikan dalam Wacana Pendidikan Tinggi Islam di Indonesia}

Internasionalisasi pendidikan dalam konteks globalisasi sejatinya merupakan akselerasi percepatan dunia di bidang pendidikan. Satu sisi, internasionalisasi mampu menawarkan beribu wajah impian akan kesuksesan, tetapi disisi lain juga tak kalah mengerikannya, menggulung 
siapapun dalam jurang kehancuran. Internasionalisasi, kata Stiglizt (Mark Haynes Daniel, 2002: 45) adalah fundamentalism globalization, yang menyediakan peluang sekaligus ancaman untuk meraih kemajuan sekaligus keterpurukan. Dengan instrumen pasar bebas, internasionalisasi akan menjadi suatu keniscayaan yang tidak menutup kemungkinan untuk terjadi, termasuk dalam dunia pendidikan tinggi yang pada dasarnya merupakan embrio dari arus internasionalisasi ilmu pengetahuan, seni dan budaya yang berjalan tanpa batas (borserless higher education market).

Internasionalisasi pendidikan menurut penulis pada dasarnya terjadi disebabkan oleh setidaknya oleh 4 faktor utama yaitu; (1) perhatian pemerintah suatu negara terhadap bidang pendidikan yang masih rendah, (2) keterbatasan dana yang dialami negara-negara berkembang, (3) peningkatan permintaan akan pendidikan tinggi yang bermutu, serta (4) kemajuan teknologi informasi. Oleh karena itu, menurut penulis dapat dimaklumi kenapa Indonesia menjadi incaran negara eksportir jasa pendidikan, karena Indonesia dengan jumlah penduduk kurang lebih 210 juta hanya mampu memiliki partisipasi penduduknya terhadap pendidikan tinggi sebesar 14\% dari jumlah penduduk usia 19-24 tahun.

Seiring dengan kenyataan itu, pendidikan pada fase selanjutnya menjadi salah satu komoditi internasional WTO yang sangat potensial melalui aplikasi General Agreement on Trade in Services (GATS) di samping sektor kesehatan, teknologi informasi dan komunikasi, dan lain sebagainya (Hanish Mc Rae, 2003: 43). Bagi negara maju, liberalisasi pendidikan dengan wajah internasionalisasi merupakan lahan subur yang mampu menghasilkan keuntungan yang sangat besar. Sejak medium 1980, di negara-negara maju, perdagangan jasa pendidikan tumbuh pesat dan telah memberikan sumbangan yang besar dibandingkan dengan sektor primer dan sekunder. Tiga negara yang paling banyak mendapatkan keuntungan itu adalah Amerika Serikat, Inggris dan Australia. Oleh karena itu dapat dipahami mengapa negara-negara maju begitu getol menyerukan internasionalisasi pendidikan melalui WTO. Betapa tidak, bagi Australia misalnya, sektor itu mampu menyumbangkan 20\% pada PDB Australia, menyerap $80 \%$ tenaga kerja dan merupakan $20 \%$ dari ekspor total negeri kanguru tersebut.

Dalam konteks itu, tidak menutup kemungkinan pendidikan tinggi 
Islam akan menjadi salah satu komoditi kompetitif dari internasionalisasi pendidikan, manakala PTAI di Indonesia mampu mendesain pendidikan tingginya sejajar dengan kebutuhan dan standar internasional. Namun, untuk menuju kearah itu, PTAI di Indonesia perlu bersikap ekstra hati-hati (antisipatif) dan melakukan persiapan guna menyongsong era itu secara bertahap, baik dalam skala internal PTAI yang bersangkutan maupun dalam dataran pemerintah selaku pengambil kebijakan pendidikan nasional. Sikap ini dimaksudkan agar perguruan tinggi di Indonesia termasuk PTAI tidak akan hanyut dalam arus hitam globalisasi pendidikan, atau dalam bahasa Alfin Tofler (1973), culture shock akan implikasi negatif globalisasi dan liberalisasi pendidikan serta mengorbankan kepentingan nasional, tetapi juga untuk memastikan tahapan ke arah itu berjalan dengan baik yang pada akhirnya pendidikan tinggi Islam PTAI di Indonesia juga bisa diharapkan dapat memberikan konstribusi terhadap negara Indonesia sebagaimana yang telah diraih oleh negara-negara maju, termasuk dalam hal ini memperbaiki daya saing tenaga kerja Indonesia di level mancanegara menjadi lebih kompetitif dan produktif. Sebagai bahan reflektif, dibahwah ini ditampilkan tabel fakta daya saing tenaga kerja Indonesia dibandingkan dengan negara Asia lainnya sebagai implikasi dari mutu sistem pendidikan negara masing-masing.

\section{Tabel 1:}

Kualitas Sistem Pendidikan dikaitkan dengan Daya Saing Tenaga Kerja pada 12 Negara di Asia

\begin{tabular}{|l|l|l|l|}
\hline \multicolumn{1}{|c|}{ Negara } & \multicolumn{1}{c|}{ Skor } & \multicolumn{1}{c|}{ Negara } & Skor \\
\hline 1. Korea Selatan & 3.09 & 7. Malaysia & 4.41 \\
\hline 2. Singapura & 3.19 & 8. Hongkong & 4.72 \\
\hline 3. Jepang & 3.50 & 9. Philipina & 5.47 \\
\hline 4. Taiwan & 3.96 & 10. Thailand & 5.96 \\
\hline 5. India & 4.24 & 11. Vietnam & 6.21 \\
\hline 6. Cina & 4.27 & 12. Indonesia & 6.56 \\
\hline
\end{tabular}

Sumber: E. Mulyasa dalam Pengantar Matrikulasi Program Beasiswa Doktor (S3) Manajemen Pendidikan di UNINUS Bandung, Agustus 2007.

Dari tabel tersebut dapat diambil kesimpulan bahwa betapa lemahnya 
daya saing SDM Indonesia bila dibandingkan dengan tenaga kerja dari negara-negara Asia lainnya. Yang menyedihkan Indonesia bahkan berada di bahwa Thailand dan Vietnam yang dalam beberapa dasawarsa yang lalu, justru kedua negara itu banyak berkiblat ke Indonesia untuk sektor pendidikannya. Bahkan yang lebih mengejutkan Malaysia mampu tampil memposisikan dirinya di atas Hongkong dan Philipina. Kenyataan ini semakin menegaskan betapa rendahnya mutu sistem pendidikan di Indonesia. Oleh karena itu PTAI melalui pendidikan tinggi Islamnya sudah saatnya untuk melakukan pembenahan secara serius bila ingin memberikan konstribusi yang signifikan kepada negara ini, sekaligus mempertegas eksistensinya sebagai salah satu perguruan tinggi nasional alternatif yang terbaik di Indonesia yang juga mampu bersaing di berbagai level kompetisi, baik nasional, regional maupun kompetisi internasional.

\section{Strategi dan Prospek Pengembangan Pendidikan Tinggi Islam dalam Aplikasi Internasionalisasi Pendidikan pada PTAI di Indonesia}

Untuk mewujudkan international qualified Islamic higher education, dalam konteks internasionalisasi pendidikan di era globalisasi saat ini, PTAI di Indonesia harus memiliki strategi pengembangan pendidikan tingginya. Hal ini dimaksudkan agar PTAI di Indonesia mampu berkembang dan maju sesuai dengan kebutuhan global tanpa harus mengorbankan kepentingankepentingan nasional. Pandangan futuristik tersebut merupakan sesuatu hal yang wajar mengingat internasionalisasi pendidikan tinggi di era globalisasi atau liberalisasi bermediasi melalui jalur pasar bebas yang sangat mungkin tidak hanya memberikan harapan untuk semakin survive, tetapi juga ancaman untuk semakin menghancurkan roda pendidikan tinggi suatu negara, apalagi perangkat infrastruktur PTAI di Indonesia, terutama swasta masih jauh dari harapan. Alih-alih bukan kemajuan yang diperoleh, tetapi justru nasib harus "gulung tikar" tidak menutup kemungkinan itu bisa terjadi manakala tidak diimbangi dengan kesiapan internal PTAI serta dukungan kebijakan pendidikan tinggi Islam yang antisipatif dalam merancang kebijakan sektor pendidikannya.

Pandangan tersebut simetris dengan apa yang pernah dikemukakan oleh Robertson (dalam James Ward, 2000: 14), bahwa internasionalisasi pendidikan sesungguhnya adalah the third wave of globalization, yang 
mampu menghantarkan suatu Negara memperoleh singgasana kedigdayaan dalam sektor tertentu, tetapi juga bisa menjerumuskan suatu Negara ke lubang kehancuran, atau hanya menjadi pecundang.

Dalam konteks itulah, ada beberapa strategi pengembangan pendidikan tinggi Islam pada PTAI di Indonesia yang dapat penulis tawarkan sebagai alternatif upaya strategis peningkatan mutu pendidikan tinggi Islam di PTAI menjadi lebih baik untuk menghadapi internasionalisasi pendidikan yang akan datang. Pertama, perbaikan manajemun mutu sistem pendidikan tinggi Islam di PTAI harus segera dilakukan secara simultan dan kontinyu. Manajemen pendidikan tingginya harus berorientasi pada pengembangan international quality academics (mutu akademis berskala internasional). Hal ini penting karena kompetisi pendidikan tinggi di era pasar bebas menuntut adanya standar mutu pendidikan yang lebih baik, yang mampu masuk ke segmen Negara manapun karena adanya global agreetment standar yang memungkinkan hal itu terjadi, termasuk bagi negera berkembang seperti Indonesia sendiri. Manajemen sistem pendidikan yang lebih baik tersebut akan mendorong tumbuh dan berkembangnya SDM yang akan dihasilkan oleh PTAI di masa yang akan datang, sekaligus membantu memposisikan Indonesia dalam berbagai tingkat kompetisi, baik regional maupun internasional menjadi semakin baik. Tentunya kebijakan perbaikan manajemen system pendidikan tinggi tersebut tetap harus mempertimbangkan potensi daerah di mana PTAI tersebut berada.

Dengan paradigma think locally act globally, PTAI di Indonesia akan mampu mengakomodir perkembangan seluruh potensi yang ada, baik daerah, nasional maupun internasional dengan selalu berpijak pada platform Islamic values morality sebagai basis aplikasi pendidikan tingginya. Sebagai komparasi prestasi SDM Indonesia di sektor pendidikan untuk tingkat Asia dapat dicermati dalam bagan di bawah ini dimana Indonesia hanya mampu memposisikan dirinya diperingkat terendah, di bawah Jepang, Korea, Australia, Hongkong, bahkan Negara Thailand yang beberapa beberapa tahun yang lalu sempat menjadikan Indonesia sebagai salah satu kiblat pendidikannya. 
Gambar 1:

Indonesia's achievements on education lag behind other countries both in terms of access and quality. Figure .... Performance on education for 2005

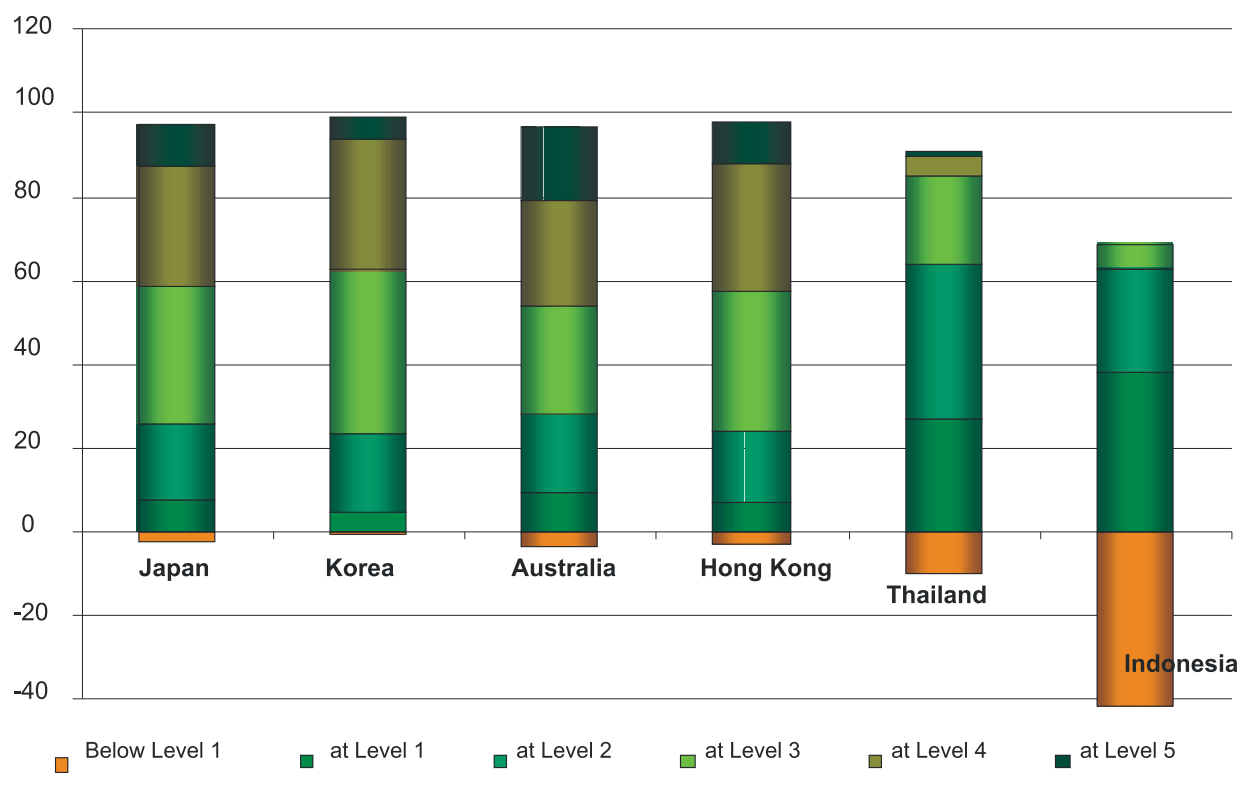

Sumber: E. Mulyasa dalam Pengantar Matrikulasi Program Beasiswa Doktor (S3) Manajemen Pendidikan di UNINUS Bandung, Agustus 2007.

Upaya penguatan manajemen sistem pendidikan tinggi Islam pada PTAI di Indonesia harus didukung oleh beberapa hal sebagai berikut; (1) implementasi jaminan mutu dan akreditasi dengan skala regional dan internasional. Kebijakan ini perlu dilakukan jika PTAI di Indonesia benarbenar ingin survive dalam berkompetisi di era globalisasi. Kebijakan itu harus diiringi dengan spirit of competitiveness dengan menyiapkan SDM dan infrastruktur pendidikan tinggi Islam yang lebih baik. Upaya itu dapat dilakukan misalnya melalui kerjasama dengan badan jaringan perguruan tinggi regional seperti Southeast Asia Ministry of Education Organization (SEMEO) untuk mendorong realisasi akreditasi tingkat regional. Setelah upaya akreditasi regional dapat berjalan dengan baik, transisi ke arah akreditasi internasional sebagai prasyarat untuk memperlebar akses 
ke masyarakat internasional tidak akan sulit. (2) otonomi pengelolaan pendidikan tinggi yang lebih matang dengan tetap memberdayakan potensi daerah. Hal ini dimaksudkan agar PTAI di daerah mampu secara lebih leluasa dalam mengelola lembaga pendidikan tingginya sesuai dengan potensi daerah serta peluang penyesuaian potensi yang ada dengan potensi internasional yang dapat dikembangkan melalui international academic networking, sehingga akan lebih mampu menyokong kiprah PTAI yang ada untuk bekerja dan menyiapkan segala sesuatunya secara lebih optimal. Hal ini penulis asumsikan karena PTAI di Indonesia secara keseluruhan memiliki karakteristik yang berbeda, baik negeri maupun swasta dan memiliki potensi daerah yang berbeda pula, serta problematika sekaligus problem solving yang tentunya sangat bervariatif. Oleh karena itu kebijakan otonomi kampus menjadi prasyarat yang mutlak harus dilakukan, yang tentunya tetap mempertimbangkan kepentingan nasional dengan selalu berkoordinasi dengan pemerintah pusat. (3) akuntabilitas aplikasi pendidikan tinggi Islam yang disupport oleh seluruh stakeholder. Akuntabilitas menjadi salah satu kunci sukses aplikasi pendidikan tinggi karena didalamnya adanya jaminan akan keterbukaan dalam pengelolaan perguruan tinggi. Dengan adanya akuntabilitas, pendidikan tinggi Islam akan mampu mengikuti percepatan perkembangan dunia pendidikan. Ada positive feedback dari seluruh stakeholder untuk bersama-sama memajukan PTAI dimana mereka saling berkepentingan (Fasli Jalal dan Dedi Supriadi, 2001: 105-17). (4) kompetensi sumber daya infrastruktur dan SDM PTAI semakin ditingkatkan melalui kebijakan resources improving yang berkelanjutan. Kebijakan ini perlu dilakukan melalui berbagai upaya, baik internal maupun eksternal. Manakala PTAI yang bersangkutan tidak memiliki sumber dana yang cukup untuk program itu, dapat disiasati dengan menjalin kerjasama dengan berbagai pihak yang konsen terhadap pengembangan dan peningkatan mutu pendidikan, baik swasta maupun negeri yang tentunya berdasarkan kesepakatan yang telah disepakati bersama. Kebijakan itu perlu dikedepankan karena eksistensi sebuah organisasi di masa depan tidak hanya ditentukan oleh internal civitasnya saja, tetapi oleh faktor eksternalnya juga (Hanish Mc Rae, 2003: 79).

Kedua, aplikasi manajemen mutu harus didukung oleh good academic atmosphere sehingga upaya peningkatan mutu akademik dapat berjalan lebih cepat dan efektif. Kondisi atmosfer akademis yang baik akan lahir 
manakala didukung oleh kesadaran holistik seluruh civitas akademika akan urgensifitas mutu pendidikan tinggi Islamnya. Upaya ini dapat dilakukan melalui pengembangan budaya akademis yang lebih sehat dan kondusif dengan mengajak seluruh civitas akademika yang ada untuk bersamasama meningkatkan proses pembelajaran dan pendidikan yang lebih baik berdasarkan komitmen mutu yang diinginkan dan diharapkan oleh semua sivitas yang ada.

Ketiga, humanistic sense of diversity harus menjadi primary supporting PTAI dalam rangka internasionalisasi pendidikan Islam yang lebih humanis dan international academic networking yang luas untuk mendukung SDM dalam negeri menjadi lebih unggul, inovatif dan produktif menjadi suatu keniscayaan sehingga ke depan PTAI dapat mereduksi pengangguran sekaligus menciptakan lulusan (row out put) yang kompetitif dalam berbagai skala kompetisi. Rasa kemanusiaan serta diversity understanding (pemahaman akan pluralitas) dalam dunia akademis mutlak diperlukan, agar pendidikan tinggi nantinya tidak hanya berorientasi pada materialisme, yang didominasi oleh kelas atas, tetapi juga memiliki sensivitas terhadap pentingnya pengembangan sumber daya manusia masa depan yang potensial walaupun dari struktur ekonomi yang kurang mampu. Artinya ada peluang untuk memperoleh kesamaan pendidikan yang baik (equality for getting good education access) bagi putera-puteri negeri tercinta ini sebagai manifestasi calon pemimpin masa depan. Secara garis besar besar pemikiran strategi pengembangan pendidikan tinggi Islam pada PTAI di Indonesia yang telah terdiskripsikan di atas dapat dipahami secara lebih sederhana melalui bagan kerangka pikir strategi pengembangan mutu sistem pendidikan di bawah ini; 
Gambar 2:

Strategi Pengembangan PTAI dalamKonteks Internasionalisasi Pendidikan

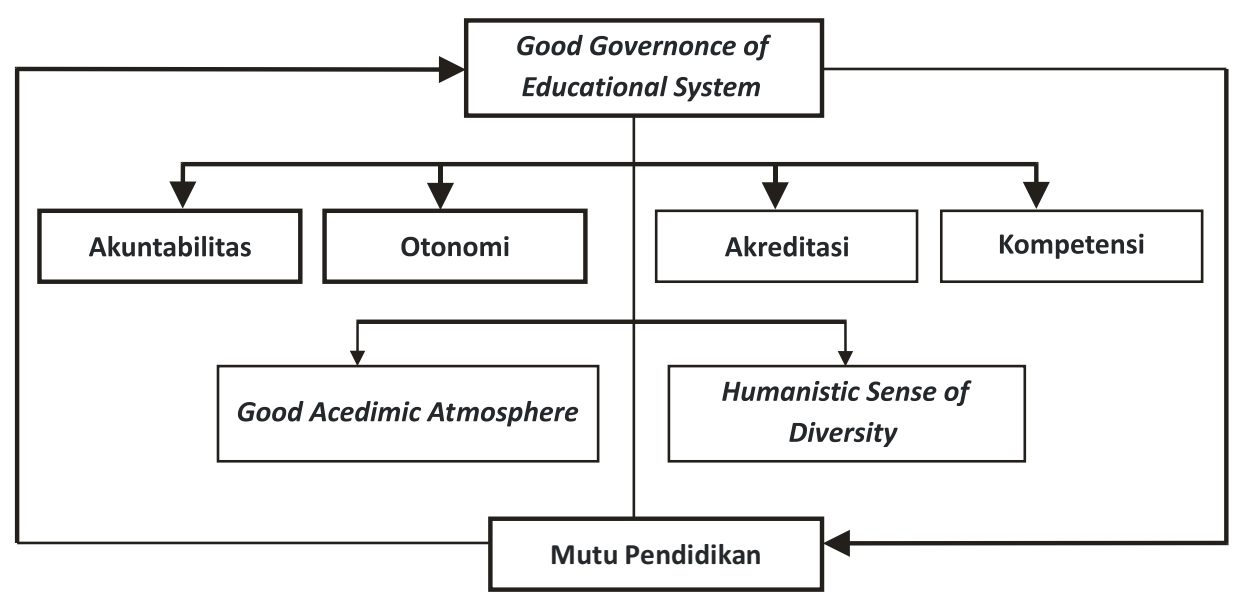

Kerangka pikir strategi pengembangan mutu pendidikan tinggi Islam bagi PTAI tersebut merupakan satu kesatuan mata rantai yang saling mempengaruhi dan memiliki ketergantungan untuk saling mensupport agar dapat berjalan secara maksimal, efektif dan efisien dalam rangka merealisasikan PTAI Indonesia yang kompetitif di era globalisasi pendidikan.

Dengan dukungan perangkat manajemen mutu sistem pendidikan tinggi Islam yang lebih baik serta strategi pengembangan pendidikan tinggi yang matang dan tepat, PTAI di Indonesia akan memiliki prospek yang baik dalam berkompetisi tidak hanya di level nasional dan regional, tetapi juga di level internasional. Di samping itu juga, setidaknya PTAI di Indonesia akan memperoleh sejumlah academic profits, seperti halnya; semakin kokohnya kiprah dan eksistensi PTAI di tengah kompetisi global, semakin luasnya international networking yang dimiliki sebagai basis pengembangan akademik dan sosial PTAI kepada masyarakat dan civitas akademiknya, serta meningkatnya mutu produk pendidikan tingginya yang diharapkan tidak hanya kompetitif dan produktif diberbagai level kompetisi, tetapi juga memiliki kepekaan sosial dan kultural kepada masyarakatnya sehingga ke depan diharapkan akan mampu mensupport kemajuan bangsa 
dalam berbagai bidang kehidupan. Atau dengan kata lain, PTAI di Indonesia mampu mencetak out put (lulusan) guna to preservenational identity, to sustain and develop the intellectual and cultural base of the society, to give inspiration and pride to citizens, and to promote dialogue for respect of cultural and social diversity

\section{Manajemen Mutu sebagai Perangkat ObligatifOperasional MutuSistem Internasionalisasi Pendidikan Tinggi pada PTAI di Indonesia}

Kajian manajemen mutu ini merupakan bentuk penjabaran dari salah satu strategi pengembangan PTAI yang telah dikemukakan diatas, yaitu perbaikan manajemen mutu sistem pendidikan tinggi Islam di PTAI. Kajian ini diharapkan mampu mendeskripsikan secara lebih komprehensif akan elan vital manajemen yang berkualitas bagi eksistensi sebuah perguruan tinggi. Edward Sallis (2001: 53-55), menegaskan bahwa manajemen mutu pendidikan akan sangat membantu institusi pendidikan setidaknya untuk 3 hal penting; pertama, manajemen mutu akan memperkuat sistem pengelolaan perguruan tinggi menjadi lebih baik. Kedua, dengan manajemen mutu, PTAI akan mampu menghasilkan produk pendidikan tinggi Islam yang lebih unggul dan kompetitif. Ketiga, dengan manajemen mutu, PTAI di Indonesia akan lebih established dalam mengaruhi roda kompetisi pendidikan tinggi, baik dalam skala nasional, regional maupun internasional.

Dalamkonteks itu pula, penulis akan melengkapi upaya pengembangan dan peningkatan manajemen mutu sistem pendidikan tinggi Islam bagi PTAI di Indonesia dengan pendekatan triple quality yang dikembangkan oleh Juran, yang terkenal dengan konsep Juran's Trilogy, yang mencakup 3 komponen utama, yaitu; (Edward Sallis, 2001: 67-68) Pertama, quality planning. Perencanaan mutu merupakan tahapan untuk menentukan dan merancang segala perangkat pendidikan tinggi, baik infrastruktur maupun lainnya seperti misi, visi, program, kebijakan, serta sketsa tahapan proses yang akan dilalui untuk dirancang secara lebih matang dan komprehensif agar mampu menghasilkan pendidikan tinggi Islam yang lebih kompetitif dan produktif berdasarkan nilai-nilai keislaman sebagai landasan aplikasinya. Aspek quality planning menjadi penting dilakukan karena perkembangan PTAI pada dasarnya juga menyesuaikan diri dari 
perkembangan masyarakat termasuk masyarakat global. Dengan kata lain, kebijakan yang dirancang adalah manifestasi dari kebutuhan dan keinginan masyarakat (social need and desire). Kedua, quality control atau dikenal dengan pengendalian mutu. Tahapan ini juga penting karena pengendalian mutu pada dasarnya merupakan jaminan mutu yang ingin dihasilkan. Dengan adanya quality control, PTAI dapat memastikan proses implementasi manajemen pendidikan tingginya dapat berjalan secara efektif dan efisien sesuai dengan perencanaan semula, baik menyangkut program pendidikan yang dijalankan, kurikulum, perangkat infrastruktur pendidikan tinggi, SDM, out put yang dirancang, maupun tingkat akselerasinya terhadap kompetisi dunia pendidikan tinggi dan dunia kerja agar tetap eksis dan survive.

Ketiga, quality improvement (peningkatan mutu). Tahapan ini merupakan upaya tindak lanjut dari proses pelaksanaan mutu dimana seluruh rencana akademis PTAI yang telah dilaksanakan dievaluasi untuk kemudian dilakukan pembenahan secara simultan dan komprehensif guna memperbaiki kelemahan yang terjadi sebelumnya. Dengan peningkatan mutu berkelanjutan, eksistensi PTAI di Indonesia akan lebih appreciable terhadap kebutuhan dan perkembangan masyarakat global. Hal ini juga dapat diartikan bahwa pengelolaan program pendidikan tinggi Islam dalam konteks internasionalisasi pendidikan sudah saatnya memperhitungkan standar mutu sebagai basis peningkatan akselerasi equality access untuk bersaing berbagai tingkat kompetisi. Secara lebih komprehensif upaya itu dapat dideskripsikan melalui bagan pengembangan triple quality dibawah ini; 


\section{Gambar 3:}

\section{Triple Quality dalam Sistem Manajemen Mutu untuk Pengembangan PTAI di Indonesia}

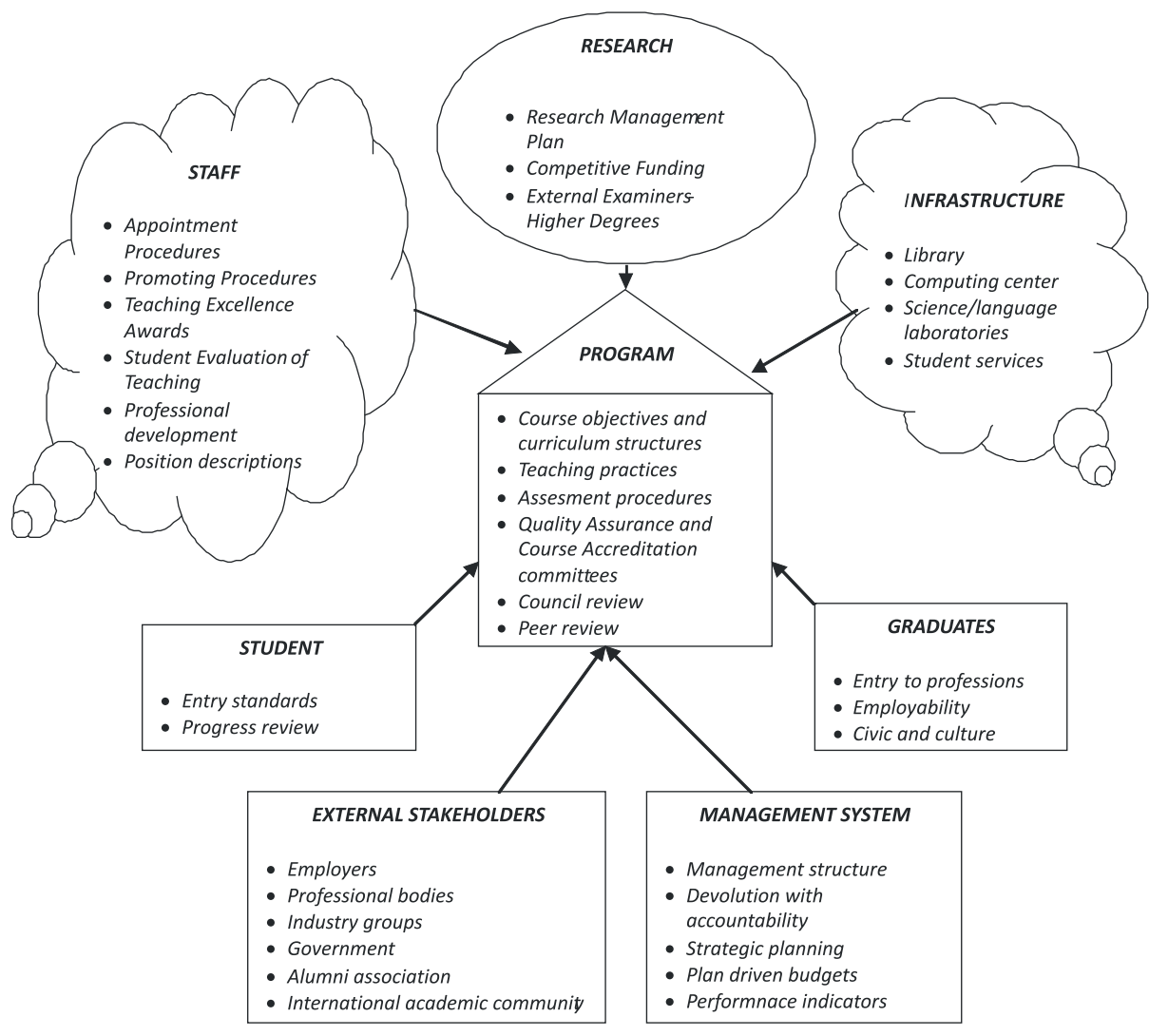

\section{Penutup}

Internasionalisasi pendidikan tinggi ke depan bukanlah suatu ironi. Tetapi realitas kekinian yang sudah semakin mengarahkan probability itu menjadi suatu kenyataan. Namun, Indonesia yang didukung oleh PTAI yang begitu besar haruslah menyiapkan perangkat kompetitif pendidikan tinggi Islam sedini mungkin sehingga ke depan PTAI di Indonesia memiliki good governonce system pendidikan tinggi yang unggul sehingga mampu berkompetisi di level internasional tanpa kehilangan Islamic morality 
character sebagai dasar aplikasinya. Dengan academic support yang lebih seatle (mapan) terutama di bidang infrastruktur pendidikan tingginya, prospek perguruan tinggi agama Islam di Indonesia, baik swasta maupun negeri dalam konteks internasionalisasi pendidikan akan mampu eksis dan survive dalam kompetisi internasional di era globalisasi saat ini.

Asumsi itu setidaknya harus didukung oleh strategi pengembangan mutu sistem pendidikan tinggi Islam yang lebih baik; Pertama, manajemen pendidikan tinggi di perguruan tinggi Islam harus mampu berorientasi pada pengembangan mutu akademik berskala internasional, sehingga academic and social needs untuk skala nasional dan regional sudah secara otomatis mampu dipenuhi. Penguatan manajemen itu harus didukung oleh; (1) implementasi akreditasi dengan skala regional dan internasional, (2) otonomi pengelolaan pendidikan tinggi yang lebih matang, (3) akuntabilitas aplikasi pendidikan tinggi Islam yang disupport oleh seluruh stakeholder, sehingga seluruh pihak dapat berpartisipasi secara aktif untuk terus membenahi dan mengevaluasi quality improvement di PTAI yang ada, (4) kompetensi sumber daya infrastruktur dan SDM PTAI semakin ditingkatkan melalui kebijakan resources improving yang berkelanjutan. Kedua, aplikasi manajemen mutu harus didukung oleh good academic atmosphere sehingga upaya peningkatan mutu akademik dapat berjalan lebih cepat dan efektif. Ketiga, humanistic sense of diversity harus menjadi primary supporting PTAI dalam rangka internasionalisasi pendidikan Islam yang lebih humanis dan international academic networking yang luas untuk mendukung SDM dalam negeri menjadi lebih unggul, inovatif dan produktif menjadi suatu keniscayaan sehingga ke depan PTAI dapat mereduksi pengangguran sekaligus menciptakan lulusan (row out put) yang kompetitif dalam berbagai skala kompetisi.

\section{DAFTAR PUSTAKA}

Abdurrahman Mas'ud, dkk. (2001). Paradigma Pendidikan Islam. Pustaka Pelajar dan Fakultas Tarbiyah IAIN Walisongo: Semarang.

Ahmad Rivan. (2005). Strategi dan Prospek Pengembangan Mutu Lulusan PTAI di Indonesia. Kedaulatan Rakyat, Yogyakarta, $23 \mathrm{Mei}$ 2005. 
Alfin Tofler. (1973). Future Shock. Pan Book Ltd: London.

Azyumardi Azra. (2000). Pendidikan Islam, Tradisi dan Modernitas Menuju Millenium Baru. Logos: Jakarta.

Badan Akreditasi Nasional Perguruan Tinggi. (2000). Guidlines for Internal Quality Assesment of Higher Education. Ministry of National Education, National Acreditation Booerd for Higher Education: Jakarta.

Bantock GH. (1998). Freedom and Autority in Educational Globalization. Faber Limited: London.

Edward Sallis. (2001). Total Quality Management in Education. Prenhall Ltd: NewYork.

E. Mulyasa dalam Pengantar Matrikulasi Program Beasiswa Doktor (S3) Manajemen Pendidikan di UNINUS Bandung, Agustus 2007.

Fasli Jalal dan Dedi Supriadi (Ed), dkk. (2001). Reformasi Pendidikan dalam Konteks Otonomi Daerah. Depdiknas-Bappenas-Adicita: Yogyakarta.

Ferry Salim. (2007). Pendidikan Indonesia Menyongsong Milenium Baru. Radar Djogja. 11 Juli 2007.

Garry Zukav. (1991). The Seat of the Soul, An Inspiring Vision of Humanity's Spiritual Destiny. Rider \& Co: London UK.

Hanish Mc Rae. (2003). Dunia di Tahun 2020, Kekuasaan, Budaya dan Kemakmuran, Wawasan tentang Masa Depan. Alih Bahasa: Anton Adiwijoyo. Bina Aksara: Jakarta.

James Ward. (2000). Reclaining International Mindset of Education in Global Era. Penguin Book: USA.

John Naisbit. (1994). Global Paradox. Alih Bahasa: Budiyanto. Bina Aksara: Jakarta.

Mark Haynes Daniel. (2002). World of Risk, Next Generation Strategy for Volatile Era in Education. John Wiley \& Son (Asia) Pte Ltd: Singapore.

Mark Ward. (2001). Universality, The Understanding Theory Behind 
Life. The Universe and Evrything: Great Britanian.

Mastuhu. (2004). Menata Ulang Pemikiran Sistem Pendidikan Nasional dalam Abad 21 (The New Mind Set of National Education in the 21st Century). Safiria Insania Press: Yogyakarta.

Suyanto dan Djihad Hisyam. (2000). Refleksi dan Reformasi Pendidikan di Indonesia Memasuki Milenium III. Adicita: Yogyakarta.

Tilaar. (2001). Manajemen Pendidikan Nasional: Kajian Pendidikan Masa Depan. Remaja Rosdakarya: Bandung. 